\title{
Translational concepts of mGluR5 in synaptic diseases of the brain
}

\section{Thomas M. Piers ${ }^{1}$, Dong Hyun Kim ${ }^{1}$, Byeong C. Kim ${ }^{1,2}$, Philip Regan ${ }^{1,3,4}$, Daniel J. Whitcomb ${ }^{1}$ and Kwangwook Cho ${ }^{1,3 *}$}

1 School of Clinical Sciences, Faculty of Medicine and Dentistry, University of Bristol, Bristol, UK

2 Department of Neurology, Chonnam National University Hospital and Medical School, Chonnam National University, Gwangju, Republic of Korea

${ }^{3}$ Henry Wellcome Laboratories for Integrative Neuroscience and Endocrinology, MRC Centre for Synaptic Plasticity, University of Bristol, Bristol, UK

${ }^{4}$ School of Physiology and Pharmacology, University of Bristol, Bristol, UK

\section{Edited by:}

Andrew Lawrence, Florey

Neuroscience Institutes, Australia

Reviewed by:

Muzamil Ahmad, Indian Institute of Integrative Medicine, India

George Perry, The University of Texas at San Antonio, USA

\section{*Correspondence:}

Kwangwook Cho, School of Clinical Sciences, Faculty of Medicine and

Dentistry, University of Bristol,

Whitson Street, Bristol BS1 3NY, UK.

e-mail: kei.cho@bristol.ac.uk
The G-protein coupled receptor family of glutamate receptors, termed metabotropic glutamate receptors (mGluRs), are implicated in numerous cellular mechanisms ranging from neural development to the processing of cognitive, sensory, and motor information. Over the last decade, multiple mGluR-related signal cascades have been identified at excitatory synapses, indicating their potential roles in various forms of synaptic function and dysfunction. This review highlights recent studies investigating mGluR5, a subtype of group I mGluRs, and its association with a number of developmental, psychiatric, and senile synaptic disorders with respect to associated synaptic proteins, with an emphasis on translational pre-clinical studies targeting mGluR5 in a range of synaptic diseases of the brain.

Keywords: mGluR5, scaffolding proteins, synaptic disease

\section{INTRODUCTION}

The metabotropic glutamate receptors (mGluRs), a sub-family of glutamate receptors, are G-protein coupled and share a common molecular morphology with other G-protein-linked receptors. Expression is widespread throughout the mammalian nervous system, including the cerebral cortex (Lopez-Bendito et al., 2002), cerebellar neurons (Berthele et al., 1999), striatal neurons, and the spinal cord (Aronica et al., 2001). Functionally, mGluRs have been implicated as essential mediators of neural development (Zirpel et al., 2000; Di Giorgi Gerevini et al., 2004; Di Giorgi-Gerevini et al., 2005; Jo et al., 2006; Castiglione et al., 2008) and more broadly as important regulators of synaptic strength in the adult brain (Jong et al., 2009; Kumar et al., 2012).

Metabotropic glutamate receptors can be subdivided into group I (mGluR 1 and 5), group II (mGluR 2 and 3), and group III (mGluR 4, 6, 7, and 8), according to G-protein coupling and mode of signal transduction. Group I receptors, which are expressed in the periphery of the postsynaptic densities of asymmetrical synapses, activate $G_{q} / G_{11}$-phospholipase $C$ mediated signaling via inositol phosphate hydrolysis and second messenger production (Figure 1; Berridge and Irvine, 1984). These second messengers are capable of initiating a myriad of cellular responses through their effects on intracellular $\mathrm{Ca}^{2+}$ stores and key enzymes, such as protein kinase C (Berridge and Irvine, 1984). In contrast to group I mGluRs, group II, and III mGluRs are distributed presynaptically. These receptors modulate cAMP signaling via the $G_{i} / G_{0}$ intracellular pathway (Anwyl, 1992; Shigemoto et al., 1997; Cartmell and Schoepp, 2000).

Group I mGluRs have been a major focus of investigation, particularly mGluR5, which is further subdivided into two structurally different receptor isoforms, named mGluR5a and
mGluR5b (Minakami et al., 1993; Joly et al., 1995). mGluR5 is found in almost all brain regions, where through development mGluR5a is the predominant isoform during the early postnatal period, and mGluR5b is more highly expressed in the adult (Minakami et al., 1993; Romano et al., 1996). During development, mGluR5 is present in cells surrounding the lateral ventricle of the embryonic brain, as well as the subventricular zone (SVZ) of the postnatal brain (Di Giorgi Gerevini et al., 2004; Di GiorgiGerevini et al., 2005). Here, during these early developmental stages, mGluR5 function is involved in both synaptogenesis and the patterning of neural circuits (Catania et al., 1994; Park et al., 2007; Wijetunge et al., 2008). Importantly, the activity of mGluR5 is influenced by a number of postsynaptic proteins, such as the scaffolding proteins Homer and Shank, which also have significant developmental roles (Tu et al., 1999; Giuffrida et al., 2005; Ronesi et al., 2012).

Given that mGluR5 regulates various mechanisms implicated in neurogenesis and synaptic maintenance, it is interesting to note emerging evidence suggesting that aberrant regulation of mGluR5 leads to mental disorders with strong developmental and synaptic origins. These include Fragile X syndrome (FXS; Dolen and Bear, 2008; Levenga et al., 2011), autism spectrum disorder (Silverman et al., 2010; Mehta et al., 2011; Won et al., 2012), and schizophrenia (Liu et al., 2008; Vardigan et al., 2010; Carlisle et al., 2011). mGluR5 dysregulation in the aged brain is now also emerging as a key mediator of Alzheimer's disease (AD) pathology, in which synaptic maintenance is strongly impaired (Lee et al., 1995, 2004; Li et al., 2009). Here we shall discuss the role of mGluR5 in synaptic diseases and review the increasing number of candidate drugs targeting the receptor for efficacious treatment in a range of developmental and synaptic diseases. 


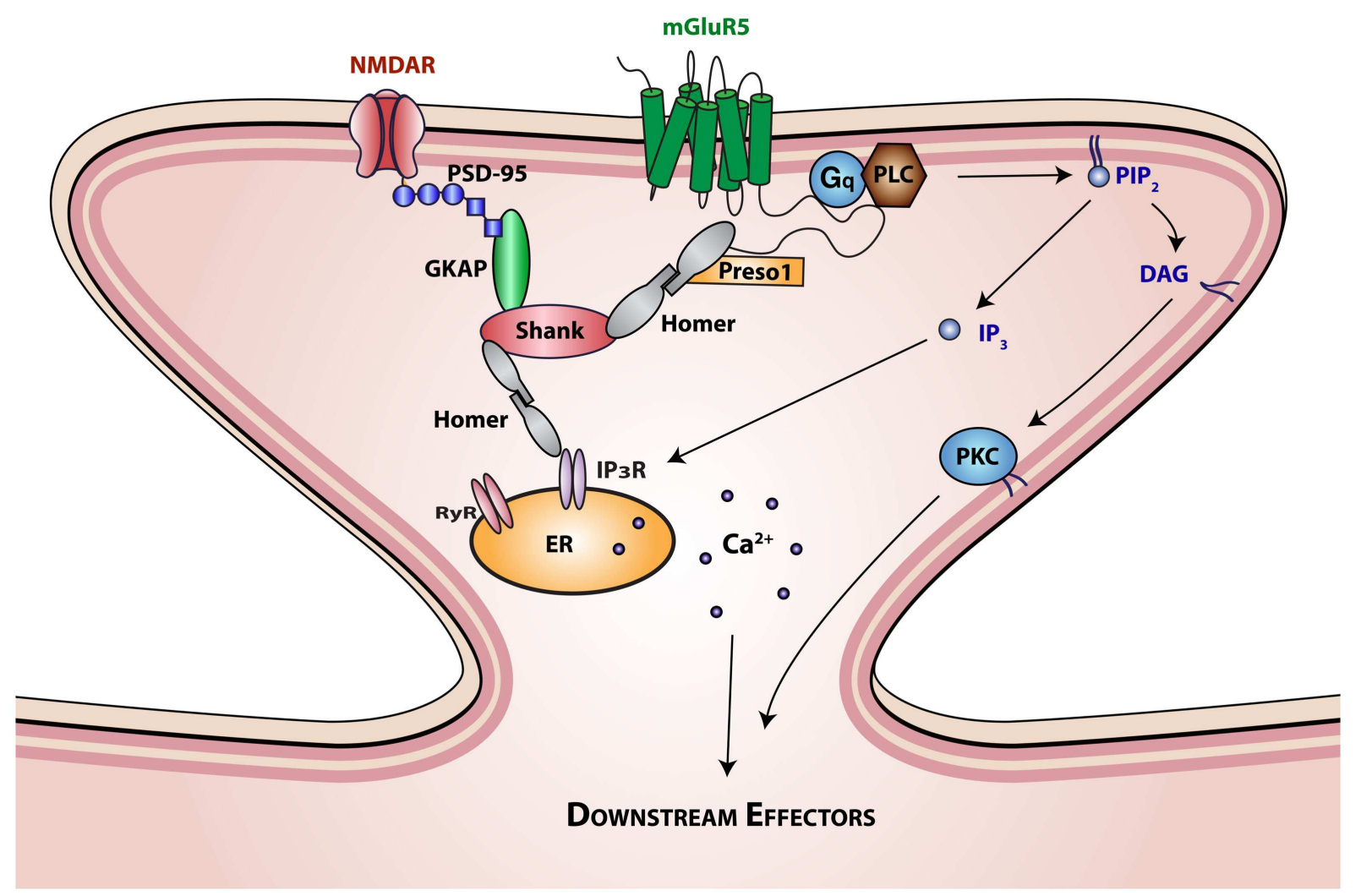

FIGURE 1 | Interaction of mGluR5 with scaffolding proteins and signaling molecules. The SH3-multiple ankyrin domain-containing protein (Shank) is a prototypical PDZ scaffolding protein. The PDZ domain of Shank interacts with the $c$ terminus of guanylate kinase-associated protein (GKAP), which is in turn associated with the ionotropic glutamatergic $N$-methyl-D-aspartate (NMDA) receptor-PSD95 complex. The proline rich domain of Shank interacts with the EVH domain of Homer proteins. Homer proteins form multimers through interactions of their coiled-coil domain and link Shank to mGluR5 and inositol triphosphate $\left(\mathrm{IP}_{3}\right)$ or ryanodine receptors. Homer interactions with mGluR5 are further regulated by Preso1 scaffolding proteins. mGluR5 activation by glutamate initiates $\mathrm{G}_{\mathrm{q}}$ protein signaling that regulates the function of phospholipase $C(P L C)$. Activation of $P L C$ results in the hydrolysis of phosphatidylinositol-4,5-bisphosphate $\left(\mathrm{PIP}_{2}\right)$ to release the second messengers 1,2-Diacylglycerol (DAG) and $I P_{3}$. DAG is the physiological activator of protein kinase $C(P K C)$, which in turn activates various intracellular signaling cascades. $I P_{3}$ binds to intracellular $I P_{3}$ receptors $\left(\mathrm{IP}_{3} \mathrm{R}\right)$ on the endoplasmic reticulum $(E R)$ membrane initiating $\mathrm{Ca}^{2+}$ release from the ER lumen into the cytoplasm, generating complex $\mathrm{Ca}^{2+}$ concentration-dependent signals, including temporal oscillations, and propagating waves.

\section{mGluR5 AND ASSOCIATED POSTSYNAPTIC PROTEINS}

Metabotropic glutamate receptors are tightly regulated by their association with scaffolding proteins. Homer, a member of a postsynaptic family of scaffolding proteins, has been shown to interact with group I mGluRs (Brakeman et al., 1997). Homer proteins exert effects on both the localization and signaling of mGluRs (Thomas, 2002). Specifically, Homer can reduce mGluR5 coupling to postsynaptic effectors, such as the $\mathrm{IP}_{3}$ receptor $\left(\mathrm{IP}_{3} \mathrm{R}\right.$; Kammermeier and Worley, 2007) and regulate mGluR-mediated protein synthesis (Ronesi and Huber, 2008). Understanding the mechanisms underlying the association between scaffold proteins and mGluRs has now become an area of significant interest. A recent study suggests that mGluR 5 regulation by proline-directed kinases, such as cyclin-dependent kinase-5 (cdk-5), leads to enhanced mGluR5-Homer binding. This in turn leads to a reduction in mGluR5-induced cytosolic $\mathrm{Ca}^{2+}$ increase, manifesting in a reduction in mGluR coupling to voltage-gated $\mathrm{Ca}^{2+}$ channels (Hu et al., 2012). The authors identified that the novel scaffolding protein Presol also served to mediate this mechanism; as a multidomain scaffolding protein, Presol localized mGluR, Homer and prolinedirected kinases, promoting the phosphorylation of mGluR, and subsequent binding of Homer (Hu et al., 2012).

Shank, a family of postsynaptic proteins that function as part of the NMDA receptor (NMDAR)-associated PSD-95 complex, is another mGluR5 regulating scaffolding protein thought critical in mGluR function. Shank clusters mGluR5 and mediates the co-clustering of Homer with PSD-95/GKAP. Thus, Shank may cross-link Homer and PSD-95 complexes in the postsynaptic density and play a role in the signaling mechanisms of both mGluR5 and NMDARs (Tu et al., 1999). Indeed, synergistic interactions between mGluR5 and NMDARs have previously been identified, whereby activation of mGluR5 enhances NMDAR function (Gregory et al., 2011; Won et al., 2012). Additionally, mGluR5 has been shown to drive experience dependent changes in NMDAR subunit composition (Matta et al., 2011). It has also been revealed that an interaction between Shank1B and Homerlb is required for mGluR5-mediated $\mathrm{IP}_{3}$ generation and ensuing $\mathrm{Ca}^{2+}$ release from intracellular stores (Sala et al., 2005), suggesting a further 
complexity to the regulation of mGluR5 function by multiple coordinating scaffolding proteins.

\section{mGIuR5 AND SYNAPTIC DISEASE}

mGluR5 has been studied as a fine regulator in both embryonic and postnatal neurogenesis (Di Giorgi Gerevini et al., 2004; Di Giorgi-Gerevini et al., 2005; Castiglione et al., 2008). mGluR5 function is therefore critical for synapse formation during brain development, suggesting that dysregulation of mGluR5 signaling might lead to developmental synaptic disorders. Accordingly, the modification of particular mGluR5 scaffolding proteins has been implicated in synaptic diseases and psychiatric disorders (Box 1). It has recently been suggested that dysregulation of Shank could be involved in schizophrenia-induced signaling cascades (Grabrucker et al., 2011). Studies have revealed that two de novo mutations in Shank3 are present in a subset of schizophrenia patients (Gauthier et al., 2010) and a Shank1 promoter variant leads to significant working memory deficits in schizophrenia (Durand et al., 2012; Lennertz et al., 2012), suggesting common Shank variants may contribute to neuropsychological dysfunctions in schizophrenia. Furthermore, limited studies also suggest mice lacking mGluR5 show schizophrenia-related behaviors including abnormal locomotor patterns, reduced pre-pulse inhibition (PPI), and deficits on performance of a short-term spatial memory task on the Y-maze (Gray et al., 2009; Wang et al., 2009; Chen et al., 2010), suggesting that positive modulation of mGluR5 function would be a viable

\section{Box 1 | Translational concepts through targeting mGluR5.}

Excessive mGluR5 activation has already been alluded to as a potential contributing factor in synaptic disorders, and a number of studies are currently testing the therapeutic potential of drugs that modify mGluR5 signaling through inhibition (Dolen et al., 2010). For these reasons, the development of mGluR5 ligands to combat synaptic diseases has become a highly attractive therapeutic area to pursue (Table 1).

\section{Autism Spectrum Disorders}

Iossifov et al. (2012) recently described overlap between autism susceptibility genes and the FMR1 gene, involved in FXS, after performing genetic sequencing of autistic children. Among the 59 new autism genes discovered, 14 were associated with fragile $X$ mental retardation protein (FMRP), which is associated with both FXS and regulation of the gene encoding mGluR5 (Sokol et al., 2011). Therefore, given the supposed role of mGluR5 in FXS and autism, the receptor provides an attractive target for drug discovery in these disorders and a number of candidate compounds including mGluR5 negative allosteric modulators (NAMs) have progressed through to Phase II/III clinical trials.

\section{Epilepsy}

Although no significant clinical trials targeting mGluR5 in epilepsy have so far been performed, group I mGluRs, have been implicated in the disease, a common neurological disorder that occurs more frequently in children than in adulthood (Hauser and Hersdorffer, 1990). Epilepsy is also the most common neurological abnormality in FXS, occurring in approximately $20 \%$ of cases, presenting as seizures and EEG abnormalities (Musumeci et al., 1988). Agonists of group I mGluRs act as convulsants (Conn and Pin, 1997), and selective group I mGluR antagonists block seizures in rodent models of epilepsy (Chapman et al., 2000; Yan et al., 2005). It is thought that mGluR1 activation plays a role in sustaining the expression of prolonged bursts, whereas mGluR5 activation may be a contributor to the induction process underlying the epileptogenesis (Stoop et al., 2003). Therefore, blockade of mGluR5 receptors may also be worth exploring as adjunctive strategies for the treatment of seizures.

\section{Schizophrenia}

There is a growing indication of a specific involvement of mGluR5 in schizophrenia. Recent therapeutic strategies for the treatment of schizophrenia focus on the pharmacological interaction between mGluR5 and NMDA receptors (NMDARs; Homayoun et al., 2004; Stefani and Moghaddam, 2010), as it is well established that mGluR5 synergistically facilitates NMDAR function to alleviate the cognitive deficits associated with schizophrenia (Awad et al., 2000; Attucci et al., 2001; Pisani et al., 2001; Rosenbrock et al., 2010). Moreover, activation of mGluR5 receptors with an agonist or positive allosteric modulator (PAM), such as CDPPB, ADX47273, MPPA, VU0092273, VU0360172, or ADX63365 has shown anti-psychotic-like properties, potentially providing therapeutic efficacy (Conn et al., 2009; Krystal et al., 2010; Niswender and Conn, 2010).

In summary, a number of neurological disorders of developmental origin are promising candidates for mGluR5-targeted therapeutics. Clearly, the balance of mGluR5 activation and inhibition is a critical parameter for healthy formation of neural circuits during development. This concept also extends into the aged brain, where dysregulation of mGluR5 function can have detrimental effects upon synaptic maintenance.

Table 1 | mGluR5 modulators in clinical trials.

\begin{tabular}{lllll}
\hline Compound & Mechanism & Indication & Clinical T phase & Company \\
\hline AFQ056 & mGluR5 NAM & $\begin{array}{l}\text { Fragile X syndrome/PD-LID/Huntington's } \\
\text { chorea/GERD }\end{array}$ & $\begin{array}{l}\text { II/III in fragile X syndrome; II in PD-LID; II } \\
\text { in Huntington's chorea (halted); Ilb in } \\
\text { GERD (halted) }\end{array}$ & Novartis \\
RO4917523 & mGluR5 antagonist & Depression/fragile X syndrome & Ila in depression; II in fragile X syndrome & Roche \\
ADX48621 & mGluR5 NAM & PD-LID, focal dystonia & II in PD-LID, focal dystonia & Addex \\
ADX63365 & mGluR5 PAM & Schizophrenia, cognition & Pre-clinical trial in schizophrenia & Addex, Merck and Co \\
STX107 & mGluR5 antagonist & Fragile X syndrome & II in fragile X syndrome & Seaside therapeutics \\
AZD2516 & mGluR5 antagonist & Chronic neuropathic pain/major depression & I/II in healthy volunteers & AstraZeneca \\
Fenobam & mGluR5 antagonist & Fragile X syndrome/pain & II/pre-clinical in bladder pain & Neuropharm
\end{tabular}


target for schizophrenia therapeutics. However, to date, research into the aberrant signaling mechanisms underlying the etiology of schizophrenia have not identified synergistic roles for scaffolding proteins and mGluR5 activity, and further studies are required to elucidate any molecular coupling of these pathways.

Deletion of Shank proteins including Shank1 and 2 is believed to produce autism spectrum disorder-like phenotypes (Sato et al., 2012; Won et al., 2012). Recent reports using Shank2 knockout mice, which exhibit an autistic phenotype, showed increased mGluR5 activity and a subsequent decrease in AMPAR synaptic transmission and excessive synapse silencing, further supporting the importance of mGluR5 regulation by scaffolding proteins in synaptogenesis and synaptic disease (Won et al., 2012).

Excessive signaling of mGluR5 is also thought to account for multiple cognitive and syndromic features of FXS, the most common inherited form of mental retardation and autism (Dolen and Bear, 2008). A fragile X mental retardation protein (FMRP) knockout model of FXS induces excessive mGluR5 activation through an increased interaction between mGluR5 and the short Homer isoform, Homer 1a (Ronesi et al., 2012). Furthermore, genetic deletion of Homer 1a, which enhances mGluR5 association with long Homer isoforms, corrected several phenotypes in the FMRP knockout model of FXS, although mGluRdependent long-term depression (LTD) was not rescued (Ronesi et al., 2012). These findings support the hypothesis that aberrant regulation of mGluR5 can lead to developmental synaptic disorders.

\section{mGIuR5 AND A $\beta$ : CONVERGENCE IN SYNAPTIC DYSFUNCTION}

It is widely accepted that certain forms of oligomeric amyloidbeta $(A \beta)$ cause neurotoxicity and contribute to the pathogenesis of AD (Huang and Mucke, 2012). For example, it is now well established that $A \beta$ oligomers, the primary pathology-inducing peptide of $\mathrm{AD}$, can cause synaptic dysfunction, manifesting in the inhibition of long-term potentiation (LTP; Walsh et al., 2002; Shankar et al., 2008; Jo et al., 2011) and the enhancement of LTD (Hsieh et al., 2006; Li et al., 2009). These two forms of synaptic plasticity, exhibited in response to differential neural activity patterns, are believed by many to be the cellular mechanism of learning and memory, the loss of which is a major symptom in $\mathrm{AD}$ (Shankar et al., 2008).

Interestingly, it is now known that mGluR5 plays an important role in synaptic plasticity. This is the result of extensive research dedicated to elucidating the involvement of mGluR5 in LTP (Bashir et al., 1993; Bortolotto and Collingridge, 1993) and LTD (Oliet et al., 1997; Bellone et al., 2008). In line with this, recent data confirms positive modulation of mGluR5 induces an enhancement of learning and memory in the normal state as well as in the NMDAR dysfunction-induced amnesic state (Homayoun and Moghaddam, 2010; Rosenbrock et al., 2010; Stefani and Moghaddam, 2010; Menard and Quirion, 2012).

Although limited data directly associates mGluR5 signaling with $\mathrm{AD}$, studies have shown potential mechanistic interactions between AD-associated molecules and mGluR5. Groups focused on molecular pathways in Autism and FXS suggest that activation of mGluR5 removes the repressive effect of the FMRP on amyloid precursor protein (APP) mRNA translation and stimulates secretion of APP (Sokol et al., 2011), the precursor to A $\beta$ peptide generation. Inhibitors of mGluR5 have been shown to reduce $A \beta$ production and to have positive effects upon disease phenotypes in rodent models of FXS and AD (Malter et al., 2010). Together, this suggests aberrant mGluR5 activation may positively regulate the processing of $A \beta$ oligomers leading to disease pathology.

Recent translational studies have also shown that $\mathrm{A} \beta$-mediated impairment of LTP can be attenuated by co-treatment with the mGluR5 antagonist, MPEP (Wang et al., 2004; Rammes et al., 2011), suggesting mGluR5 may be an efficacious target for the treatment of AD. However, although MPEP is characterized as an effective mGluR5 antagonist, a non-specific action as a noncompetitive NMDAR antagonist could potentially provide the observed neuroprotective effects (O'Leary et al., 2000).

Evidence for a direct mechanistic interaction between mGluR5 and $\mathrm{A} \beta$ was identified by Renner et al. (2010) using quantum dot tagged oligomers of $A \beta$ to show that clustering of $\mathrm{A} \beta$ at the membrane greatly reduced the ability of mGluR5 to laterally diffuse from the synapse, resulting in facilitation of mGluR5-mediated signaling. Additionally, A $\beta$ binding to the neuronal surface of hippocampal cultured neurons from mGluR5 knockout mice was greatly reduced, suggesting that mGluR5 may play a reciprocal role in "scaffolding" $A \beta$ oligomer clusters to the synapses. Together these findings hint at a synergistic interaction between $\mathrm{A} \beta$ and mGluR5, resulting in the over-activation of mGluR5 with subsequent pathological effects upon NMDAR function and $\mathrm{Ca}^{2+}$ homeostasis (Renner et al., 2010).

Finally, $A \beta$-mediated activation of mGluR5 may inhibit the function of muscarinic acetylcholine receptors (mAChR) leading to cholinergic hypofunction, a hallmark of $\mathrm{AD}$ pathogenesis closely linked to $\mathrm{A} \beta$ and Tau neuropathologies (Fisher, 2012). Indeed, aberrant expression of mGluR5 leads to the inhibition of mAChR-mediated long-term synaptic depression in the perirhinal cortex (Jo et al., 2006) and acute nicotine-mediated enhancement of LTP in the rat dentate gyrus can be inhibited by MPEP (Welsby et al., 2006). Thus, mGluR5 dysregulation has been proposed as a key step in AD pathology, marking mGluR5 as a possible target to tackle synaptic dysfunction in AD. However, more effort to shed light on the mechanism of action of mGluR5 will be required prior to the effective development of receptor-based treatments for $\mathrm{AD}$.

\section{CONCLUDING REMARKS}

In the past several years, significant progress has been made into the understanding of mGluR5 receptor function in health and disease. Studies suggest that the mGluR5 receptor has an important role in synaptogenesis and the regulation of synaptic plasticity. Thus, it seems aberrant mGluR5 regulation and signaling may play a part in a number of synaptic disorders, including a novel role in $\mathrm{AD}$. Therapeutic treatments are slowly coming to the fore in many of these disorders. However, more research into the underlying involvement of this promiscuous receptor in synaptic-related disorders will ensure more efficacious treatments can be developed in the future. 


\section{REFERENCES}

Anwyl, R. (1992). Metabotropic glutamate receptors: electrophysiological properties and role in plasticity. Rev. Neurosci. 3, 217-231.

Aronica, E., Catania, M. V., Geurts, J., Yankaya, B., and Troost, D. (2001). Immunohistochemical localization of group I and II metabotropic glutamate receptors in control and amyotrophic lateral sclerosis human spinal cord: upregulation in reactive astrocytes. Neuroscience 105, 509-520.

Attucci, S., Carla, V., Mannaioni, G., and Moroni, F. (2001). Activation of type 5 metabotropic glutamate receptors enhances NMDA responses in mice cortical wedges. Br. J. Pharmacol. 132, 799-806.

Awad, H., Hubert, G. W., Smith, Y., Levey, A. I., and Conn, P. J. (2000). Activation of metabotropic glutamate receptor 5 has direct excitatory effects and potentiates NMDA receptor currents in neurons of the subthalamic nucleus. J. Neurosci. 20, 7871-7879.

Bashir, Z. I., Bortolotto, Z. A., Davies, C. H., Berretta, N., Irving, A. J., Seal, A. J., et al. (1993). Induction of LTP in the hippocampus needs synaptic activation of glutamate metabotropic receptors. Nature 363, 347-350.

Bellone, C., Luscher, C., and Mameli, M. (2008). Mechanisms of synaptic depression triggered by metabotropic glutamate receptors. Cell. Mol. Life Sci. 65, 2913-2923.

Berridge, M. J., and Irvine, R. F. (1984). Inositol trisphosphate, a novel second messenger in cellular signal transduction. Nature 312, 315-321.

Berthele, A., Platzer, S., Laurie, D. J., Weis, S., Sommer, B., Zieglgansberger, W., et al. (1999). Expression of metabotropic glutamate receptor subtype mRNA (mGluR1-8) in human cerebellum. Neuroreport 10, 3861-3867.

Bortolotto, Z. A., and Collingridge, G. L. (1993). Characterisation of LTP induced by the activation of glutamate metabotropic receptors in area CAl of the hippocampus. Neuropharmacology 32, 1-9.

Brakeman, P. R., Lanahan, A. A., O’Brien, R., Roche, K., Barnes, C. A., Huganir, R. L., et al. (1997). Homer: a protein that selectively binds metabotropic glutamate receptors. Nature 386, 284-288.

Carlisle, H. J., Luong, T. N., MedinaMarino, A., Schenker, L., Khorosheva, E., Indersmitten, T., et al. (2011). Deletion of densin180 results in abnormal behaviors associated with mental illness and reduces mGluR5 and DISC1 in the postsynaptic density fraction. $J$. Neurosci. 31, 16194-16207.

Cartmell, J., and Schoepp, D. D. (2000). Regulation of neurotransmitter release by metabotropic glutamate receptors. J. Neurochem. 75, 889-907.

Castiglione, M., Calafiore, M., Costa, L., Sortino, M. A., Nicoletti, F., and Copani, A. (2008). Group I metabotropic glutamate receptors control proliferation, survival and differentiation of cultured neural progenitor cells isolated from the subventricular zone of adult mice. Neuropharmacology 55, 560-567.

Catania, M. V., Landwehrmeyer, G. B., Testa, C. M., Standaert, D. G., Penney, J. B. Jr., and Young, A. B. (1994). Metabotropic glutamate receptors are differentially regulated during development. Neuroscience 61, 481-495.

Chapman, A. G., Nanan, K., Williams, M., and Meldrum, B. S. (2000). Anticonvulsant activity of two metabotropic glutamate group I antagonists selective for the mGlu5 receptor: 2-methyl-6(phenylethynyl)-pyridine (MPEP), and (E)-6-methyl-2-styryl-pyridine (SIB 1893). Neuropharmacology 39, 1567-1574.

Chen, H. H., Stoker, A., and Markou, A. (2010). The glutamatergic compounds sarcosine and $\mathrm{N}$ acetylcysteine ameliorate prepulse inhibition deficits in metabotropic glutamate 5 receptor knockout mice. Psychopharmacology (Berl.) 209, 343-350.

Conn, P. J., Lindsley, C. W., and Jones, C. K. (2009). Activation of metabotropic glutamate receptors as a novel approach for the treatment of schizophrenia. Trends Pharmacol. Sci. 30, 25-31.

Conn, P. J., and Pin, J. P. (1997). Pharmacology and functions of metabotropic glutamate receptors. Annu. Rev. Pharmacol. Toxicol. 37, 205-237.

Di Giorgi Gerevini, V. D., Caruso, A., Cappuccio, I., Ricci Vitiani, L., Romeo, S., Della Rocca, C., et al. (2004). The mGlu5 metabotropic glutamate receptor is expressed in zones of active neurogenesis of the embryonic and postnatal brain. Brain Res. Dev. Brain Res. 150, 17-22.

Di Giorgi-Gerevini, V., Melchiorri, D., Battaglia, G., Ricci-Vitiani, L., Ciceroni, C., Busceti, C. L., et al. (2005). Endogenous activation of metabotropic glutamate receptors supports the proliferation and survival of neural progenitor cells. Cell Death Differ. 12, 1124-1133.

Dolen, G., and Bear, M. F. (2008). Role for metabotropic glutamate receptor 5 (mGluR5) in the pathogenesis of fragile X syndrome. J. Physiol. (Lond.) 586, 1503-1508.

Dolen, G., Carpenter, R. L., Ocain, T. D., and Bear, M. F. (2010). Mechanismbased approaches to treating fragile X. Pharmacol. Ther. 127, 78-93.

Durand, C. M., Perroy, J., Loll, F., Perrais, D., Fagni, L., Bourgeron, T., et al. (2012). SHANK3 mutations identified in autism lead to modification of dendritic spine morphology via an actin-dependent mechanism. Mol. Psychiatry 17, 71-84.

Fisher, A. (2012). Cholinergic modulation of amyloid precursor protein processing with emphasis on M1 muscarinic receptor: perspectives and challenges in treatment of Alzheimer's disease. J. Neurochem. 120(Suppl. 1), 22-33.

Gauthier, J., Champagne, N., Lafrenière, R. G., Xiong, L., Spiegelman, D., Brustein, E., et al. (2010). De novo mutations in the gene encoding the synaptic scaffolding protein SHANK3 in patients ascertained for schizophrenia. Proc. Natl. Acad. Sci. U.S.A. 107, 7863-7868.

Giuffrida, R., Musumeci, S., D’Antoni, S., Bonaccorso, C. M., GiuffridaStella, A. M., Oostra, B. A., et al. (2005). A reduced number of metabotropic glutamate subtype 5 receptors are associated with constitutive homer proteins in a mouse model of fragile $\mathrm{X}$ syndrome. $J$. Neurosci. 25, 8908-8916.

Grabrucker, A. M., Schmeisser, M. J., Schoen, M., and Boeckers, T. M. (2011). Postsynaptic ProSAP/Shank scaffolds in the cross-hair of synaptopathies. Trends Cell Biol. 21, 594-603.

Gray, L., van den Buuse, M., Scarr, E., Dean, B., and Hannan, A. J. (2009). Clozapine reverses schizophrenia-related behaviours in the metabotropic glutamate receptor 5 knockout mouse: association with $\mathrm{N}$-methyl-D-aspartic acid receptor up-regulation. Int. $J$. Neuropsychopharmacol. 12, 45-60.

Gregory, K. J., Dong, E. N., Meiler, J., and Conn, P. J. (2011). Allosteric modulation of metabotropic glutamate receptors: structural insights and therapeutic potential. Neuropharmacology 60, 66-81.

Hauser, W., and Hersdorffer, D. (1990). Epilepsy: Frequency, Causes and Consequences. New York: Demos.

Homayoun, H., and Moghaddam, B. (2010). Group 5 metabotropic glutamate receptors: role in modulating cortical activity and relevance to cognition. Eur. J. Pharmacol. 639, 33-39.

Homayoun, H., Stefani, M. R., Adams, B. W., Tamagan, G. D., and Moghaddam, B. (2004). Functional interaction between NMDA and mGlu5 receptors: effects on working memory, instrumental learning, motor behaviors, and dopamine release. Neuropsychopharmacology 29, 1259-1269.

Hsieh, H., Boehm, J., Sato, C., Iwatsubo, T., Tomita, T., Sisodia, S., et al. (2006). AMPAR removal underlies Abeta-induced synaptic depression and dendritic spine loss. Neuron 52, 831-843.

Hu, J. H., Yang, L., Kammermeier, P. J., Moore, C. G., Brakeman, P. R., Tu, J., et al. (2012). Presol dynamically regulates group I metabotropic glutamate receptors. Nat. Neurosci. 15 , 836-844.

Huang, Y., and Mucke, L. (2012). Alzheimer mechanisms and therapeutic strategies. Cell 148, 1204-1222.

Iossifov, I., Ronemus, M., Levy, D., Wang, Z., Hakker, I., Rosenbaum, J., et al. (2012). De novo gene disruptions in children on the autistic spectrum. Neuron 74, 285-299.

Jo, J., Ball, S. M., Seok, H., Oh, S. B., Massey, P. V., Molnar, E., et al. (2006). Experience-dependent modification of mechanisms of long-term depression. Nat. Neurosci. 9, 170-172.

Jo, J., Whitcomb, D. J., Olsen, K. M., Kerrigan, T. L., Lo, S. C., Bru-Mercier G., et al. (2011). Abeta(1-42) inhibition of LTP is mediated by a signaling pathway involving caspase-3, Akt1 and GSK-3beta. Nat. Neurosci. 14, 545-547.

Joly, C., Gomeza, J., Brabet, I., Curry, K., Bockaert, J., and Pin, J. P. (1995). Molecular, functional, and pharmacological characterization of the metabotropic glutamate receptor type 5 splice variants: comparison with mGluR1. J. Neurosci. 15, 3970-3981.

Jong, Y. J., Kumar, V., and O’Malley, K. L. (2009). Intracellular metabotropic glutamate receptor 5 (mGluR5) activates signaling cascades distinct from cell surface counterparts. J. Biol. Chem. 284, 35827-35838.

Kammermeier, P. J., and Worley, P. F. (2007). Homer la uncouples metabotropic glutamate receptor 5 from postsynaptic effectors. Proc. Natl. Acad. Sci. U.S.A. 104, 6055-6060.

Krystal, J. H., Mathew, S. J., D'Souza, D. C., Garakani, A., Gunduz-Bruce, 
H., and Charney, D. S. (2010). Potential psychiatric applications of metabotropic glutamate receptor agonists and antagonists. CNS Drugs 24, 669-693.

Kumar, V., Fahey, P. G., Jong, Y. J., Ramanan, N., and O'Malley, K. L. (2012). Activation of intracellular metabotropic glutamate receptor 5 in striatal neurons leads to up-regulation of genes associated with sustained synaptic transmission including Arc/Arg3.1 protein. J. Biol. Chem. 287, 5412-5425.

Lee, H. G., Ogawa, O., Zhu, X., O’Neill, M. J., Petersen, R. B., Castellani, R. J., et al. (2004). Aberrant expression of metabotropic glutamate receptor 2 in the vulnerable neurons of Alzheimer's disease. Acta Neuropathol. 107, 365-371.

Lee, R. K., Wurtman, R. J., Cox, A. J., and Nitsch, R. M. (1995). Amyloid precursor protein processing is stimulated by metabotropic glutamate receptors. Proc. Natl. Acad. Sci. U.S.A. 92, 8083-8087.

Lennertz, L., Wagner, M., Wolwer, W., Schuhmacher, A., Frommann, I., Berning, J., et al. (2012). A promoter variant of SHANK1 affects auditory working memory in schizophrenia patients and in subjects clinically at risk for psychosis. Eur. Arch. Psychiatry Clin. Neurosci. 262, 117-124.

Levenga, J., Hayashi, S., de Vrij, F. M., Koekkoek, S. K., van der Linde, H. C., Nieuwenhuizen, I., et al. (2011). AFQ056, a new mGluR5 antagonist for treatment of fragile $\mathrm{X}$ syndrome. Neurobiol. Dis. 42, 311-317.

Li, S., Hong, S., Shepardson, N. E., Walsh, D. M., Shankar, G. M., and Selkoe, D. (2009). Soluble oligomers of amyloid beta protein facilitate hippocampal long-term depression by disrupting neuronal glutamate uptake. Neuron 62, 788-801.

Liu, F., Grauer, S., Kelley, C., Navarra, R., Graf, R., Zhang, G., et al. (2008). ADX47273 [S-(4-fluoro-phenyl)-\{3-[3-(4fluoro-phenyl)-[1,2,4]-oxadiazol5-yl]-piperidin-1-yl\}-methanone]: a novel metabotropic glutamate receptor 5-selective positive allosteric modulator with preclinical antipsychotic-like and procognitive activities. J. Pharmacol. Exp. Ther. $327,827-839$

Lopez-Bendito, G., Shigemoto, R., Fairen, A., and Lujan, R. (2002). Differential distribution of group I metabotropic glutamate receptors during rat cortical development. Cereb. Cortex 12, 625-638.
Malter, J. S., Ray, B. C., Westmark, P. R., and Westmark, C. J. (2010). Fragile $\mathrm{X}$ syndrome and Alzheimer's disease: another story about APP and beta-amyloid. Curr. Alzheimer Res. 7, 200-206.

Matta, J. A., Ashby, M. C., SanzClemente, A., Roche, K. W., and Isaac, J. T. (2011). mGluR5 and NMDA receptors drive the experience- and activity-dependent NMDA receptor NR2B to NR2A subunit switch. Neuron 70, 339-351.

Mehta, M. V., Gandal, M. J., and Siegel, S. J. (2011). mGluR5antagonist mediated reversal of elevated stereotyped, repetitive behaviors in the VPA model of autism. PLoS ONE 6, e26077. doi:10.1371/journal.pone.0026077

Menard, C., and Quirion, R. (2012). Successful cognitive aging in rats: a role for mGluR5 glutamate receptors, homer 1 proteins and downstream signaling pathways. PLoS ONE 7, e28666. doi:10.1371/journal.pone.0028666

Minakami, R., Katsuki, F., and Sugiyama, H. (1993). A variant of metabotropic glutamate receptor subtype 5: an evolutionally conserved insertion with no termination codon. Biochem. Biophys. Res. Commun. 194, 622-627.

Musumeci, S. A., Colognola, R. M., Ferri, R., Gigli, G. L., Petrella, M. A., Sanfilippo, S., et al. (1988). Fragile$\mathrm{X}$ syndrome: a particular epileptogenic EEG pattern. Epilepsia 29, 41-47.

Niswender, C. M., and Conn, P. J. (2010). Metabotropic glutamate receptors: physiology, pharmacology, and disease. Annu. Rev. Pharmacol. Toxicol. 50, 295-322.

O'Leary, D. M., Movsesyan, V., Vicini, S., and Faden, A. I. (2000). Selective mGluR5 antagonists MPEP and SIB1893 decrease NMDA or glutamatemediated neuronal toxicity through actions that reflect NMDA receptor antagonism. Br. J. Pharmacol. 131, 1429-1437.

Oliet, S. H., Malenka, R. C., and Nicoll, R. A. (1997). Two distinct forms of long-term depression coexist in CA1 hippocampal pyramidal cells. Neuron 18, 969-982.

Park, H., Varadi, A., Seok, H., Jo, J., Gilpin, H., Liew, C. G., et al. (2007). mGluR5 is involved in dendrite differentiation and excitatory synaptic transmission in NTERA2 human embryonic carcinoma cellderived neurons. Neuropharmacology 52, 1403-1414.

Pisani, A., Gubellini, P., Bonsi, P., Conquet, F., Picconi, B., Centonze, D., et al. (2001). Metabotropic glutamate receptor 5 mediates the potentiation of N-methyl-D-aspartate responses in medium spiny striatal neurons. Neuroscience 106, 579-587.

Rammes, G., Hasenjager, A., SrokaSaidi, K., Deussing, J. M., and Parsons, C. G. (2011). Therapeutic significance of NR2B-containing NMDA receptors and mGluR5 metabotropic glutamate receptors in mediating the synaptotoxic effects of beta-amyloid oligomers on longterm potentiation (LTP) in murine hippocampal slices. Neuropharmacology 60, 982-990.

Renner, M., Lacor, P. N., Velasco, P. T., $\mathrm{Xu}$, J., Contractor, A., Klein, W. L., et al. (2010). Deleterious effects of amyloid beta oligomers acting as an extracellular scaffold for mGluR5. Neuron 66, 739-754.

Romano, C., van den Pol, A. N., and O'Malley, K. L. (1996). Enhanced early developmental expression of the metabotropic glutamate receptor mGluR5 in rat brain: protein, mRNA splice variants, and regional distribution. J. Comp. Neurol. 367, 403-412.

Ronesi, J. A., Collins, K. A., Hays, S. A., Tsai, N. P., Guo, W., Birnbaum, S. G., et al. (2012). Disrupted Homer scaffolds mediate abnormal mGluR5 function in a mouse model of fragile X syndrome. Nat. Neurosci. 15, 431-440, S431.

Ronesi, J. A., and Huber, K. M. (2008). Homer interactions are necessary for metabotropic glutamate receptorinduced long-term depression and translational activation. J. Neurosci. 28, 543-547.

Rosenbrock, H., Kramer, G., Hobson, S., Koros, E., Grundl, M., Grauert, M., et al. (2010). Functional interaction of metabotropic glutamate receptor 5 and NMDAreceptor by a metabotropic glutamate receptor 5 positive allosteric modulator. Eur. J. Pharmacol. 639, 40-46.

Sala, C., Roussignol, G., Meldolesi, J., and Fagni, L. (2005). Key role of the postsynaptic density scaffold proteins Shank and Homer in the functional architecture of $\mathrm{Ca} 2+$ homeostasis at dendritic spines in hippocampal neurons. J. Neurosci. $25,4587-4592$.

Sato, D., Lionel, A. C., Leblond, C. S., Prasad, A., Pinto, D., Walker, S., et al. (2012). SHANK1 deletions in males with autism spectrum disorder. Am. J. Hum. Genet. 90, 879-887.

Shankar, G. M., Li, S., Mehta, T. H., Garcia-Munoz, A., Shepardson, N.
E., Smith, I., et al. (2008). Amyloidbeta protein dimers isolated directly from Alzheimer's brains impair synaptic plasticity and memory. Nat. Med. 14, 837-842.

Shigemoto, R., Kinoshita, A., Wada, E., Nomura, S., Ohishi, H., Takada, M., et al. (1997). Differential presynaptic localization of metabotropic glutamate receptor subtypes in the rat hippocampus. J. Neurosci. 17, 7503-7522.

Silverman, J. L., Tolu, S. S., Barkan, C. L., and Crawley, J. N. (2010). Repetitive self-grooming behavior in the BTBR mouse model of autism is blocked by the mGluR5 antagonist MPEP. Neuropsychopharmacology 35, 976-989.

Sokol, D. K., Maloney, B., Long, J. M., Ray, B., and Lahiri, D. K. (2011) Autism, Alzheimer disease, and fragile X: APP, FMRP, and mGluR5 are molecular links. Neurology 76, 1344-1352.

Stefani, M. R., and Moghaddam, B. (2010). Activation of type 5 metabotropic glutamate receptors attenuates deficits in cognitive flexibility induced by NMDA receptor blockade. Eur. J. Pharmacol. 639, 26-32.

Stoop, R., Conquet, F., and Pralong, E. (2003). Determination of group I metabotropic glutamate receptor subtypes involved in the frequency of epileptiform activity in vitro using mGluR1 and mGluR5 mutant mice. Neuropharmacology 44, 157-162.

Thomas, U. (2002). Modulation of synaptic signalling complexes by Homer proteins. J. Neurochem. 81 , 407-413.

Tu, J. C., Xiao, B., Naisbitt, S., Yuan, J. P., Petralia, R. S., Brakeman, P., et al. (1999). Coupling of mGluR/Homer and PSD-95 complexes by the Shank family of postsynaptic density proteins. Neuron 23, 583-592.

Vardigan, J. D., Huszar, S. L., McNaughton, C. H., Hutson, P. H., and Uslaner, J. M. (2010). MK-801 produces a deficit in sucrose preference that is reversed by clozapine, $\mathrm{D}$-serine, and the metabotropic glutamate 5 receptor positive allosteric modulator CDPPB: relevance to negative symptoms associated with schizophrenia? Pharmacol. Biochem. Behav. 95, 223-229.

Walsh, D. M., Klyubin, I., Fadeeva, J. V., Cullen, W. K., Anwyl, R., Wolfe, M. S., et al. (2002). Naturally secreted oligomers of amyloid beta protein potently inhibit hippocampal longterm potentiation in vivo. Nature 416, 535-539. 
Wang, H., Westin, L., Nong, Y., Birnbaum, S., Bendor, J., Brismar, H., et al. (2009). Norbin is an endogenous regulator of metabotropic glutamate receptor 5 signaling. Science 326, 1554-1557.

Wang, Q., Walsh, D. M., Rowan, M. J., Selkoe, D. J., and Anwyl, R. (2004). Block of long-term potentiation by naturally secreted and synthetic amyloid betapeptide in hippocampal slices is mediated via activation of the kinases c-Jun N-terminal kinase, cyclin-dependent kinase 5, and p38 mitogen-activated protein kinase as well as metabotropic glutamate receptor type 5. J. Neurosci. 24, 3370-3378.

Welsby, P., Rowan, M., and Anwyl, R. (2006). Nicotinic receptor-mediated enhancement of long-term potentiation involves activation of metabotropic glutamate receptors and ryanodine-sensitive calcium stores in the dentate gyrus. Eur. J. Neurosci. 24, 3109-3118.

Wijetunge, L. S., Till, S. M., Gillingwater,

T. H., Ingham, C. A., and Kind, P. C. (2008). mGluR5 regulates glutamate-dependent development of the mouse somatosensory cortex. J. Neurosci. 28, 13028-13037.

Won, H., Lee, H. R., Gee, H. Y., Mah, W., Kim, J. I., Lee, J., et al. (2012). Autistic-like social behaviour in Shank2-mutant mice improved by restoring NMDA receptor function. Nature 486, 261-265.

Yan, Q. J., Rammal, M., Tranfaglia, M., and Bauchwitz, R. P. (2005).
Suppression of two major fragile $\mathrm{X}$ syndrome mouse model phenotypes by the mGluR5 antagonist MPEP. Neuropharmacology 49, 1053-1066.

Zirpel, L., Janowiak, M. A., Taylor, D. A., and Parks, T. N. (2000). Developmental changes in metabotropic glutamate receptor-mediated calcium homeostasis. J. Comp. Neurol. 421 , 95-106.

Conflict of Interest Statement: The authors declare that the research was conducted in the absence of any commercial or financial relationships that could be construed as a potential conflict of interest.

Received: 31 August 2012; paper pending published: 01 October 2012; accepted:
06 November 2012; published online: 27 November 2012.

Citation: Piers TM, Kim DH, Kim BC, Regan P, Whitcomb DJ and Cho $K$ (2012) Translational concepts of mGluR5 in synaptic diseases of the brain. Front. Pharmacol. 3:199. doi: 10.3389/fphar.2012.00199

This article was submitted to Frontiers in Neuropharmacology, a specialty of Frontiers in Pharmacology.

Copyright (c) 2012 Piers, Kim, Kim, Regan, Whitcomb and Cho. This is an open-access article distributed under the terms of the Creative Commons Attribution License, which permits use, distribution and reproduction in other forums, provided the original authors and source are credited and subject to any copyright notices concerning any third-party graphics etc. 